\title{
Sibuyan Island in the Philippines - threatened and in need of conservation
}

\author{
S. M. Goodman and N. R. Ingle
}

In the spring of 1992 a group of zoologists completed a faunal survey of Sibuyan Island, a small mountainous island in the central Philippines. This island, which is oceanic in origin and during the Pleistocene at least was not connected to any other island mass, has an exceptional amount of intact primary forest, including lowland forest, a habitat that has all but been destroyed in the Philippines. The mammalian fauna of Sibuyan Island is exceptionally high in endemic species and also contains many other species that are threatened throughout the Philippines. Current logging operations severely threaten the remaining areas of lowland forest on the island. With forests of the Philippines under intense pressure, the most realistic hope for conservation lies in the protection of forests on islands where the population and political pressures are less intense. Sibuyan Island is an excellent candidate for such initiative.

The Republic of the Philippines consists of over 7000 islands and islets. Knowledge of the terrestrial vertebrate fauna of even the larger islands is incomplete, as shown by continued discoveries of new species, including more than 10 mammals since' 1980 (Heaney et al., 1987). On about 15 per cent of the islands, terrestrial vertebrates are known to some extent but very few islands have a well-documented vertebrate fauna. Attempts to synthesize available data suffer from the lack of comprehensive, detailed inventories from representative areas that could serve as benchmarks, particularly the smaller and more remote islands. Thus biogeographical analyses that are highly relevant to conservation biology are severely hampered. Efforts to document and understand the biotic diversity of the Philippines are further complicated by the fact that the vast majority of islands have been cleared of most or all of their lowland forest. For most groups of terrestrial vertebrates, the lowland forest holds (or held) the highest species diversity of any habitat. In numerous cases, the only information available on animals that occurred in a deforested area is from surveys conducted before logging operations started, and is generally in the form of museum specimens.
A significant portion of the current distributional patterns of vertebrates in the Philippines can be explained by changes in ocean depth during the middle to late Pleistocene, which resulted in a lowering of sea-level, establishment of land connections between various islands, and subsequent colonization by animals (Brown and Alcala, 1970; Heaney, 1986; Dickinson et al., 1991). To date, almost all studies of terrestrial vertebrates on smaller islands have been conducted on those connected by land-bridges to much larger islands during the late Pleistocene (e.g. Catanduanes, Marinduque, Ticao, Dinagat, Siargao). The only exception is Camiguin Sur, and island of oceanic origin, separated from Mindanao Island by a strait $8 \mathrm{~km}$ wide and $385 \mathrm{~m}$ deep. It is almost certain that these two islands were not connected during the Pleistocene (Heaney, 1984). Information on the birds and mammals of Camiguin Sur is incomplete. Hitherto, there has been no detailed study in the Philippines of the birds or mammals found on a small island of oceanic origin and surrounded by deep water. This is unfortunate, because information on the vertebrates occurring on isolated oceanic islands allow important biogeographical questions to be 


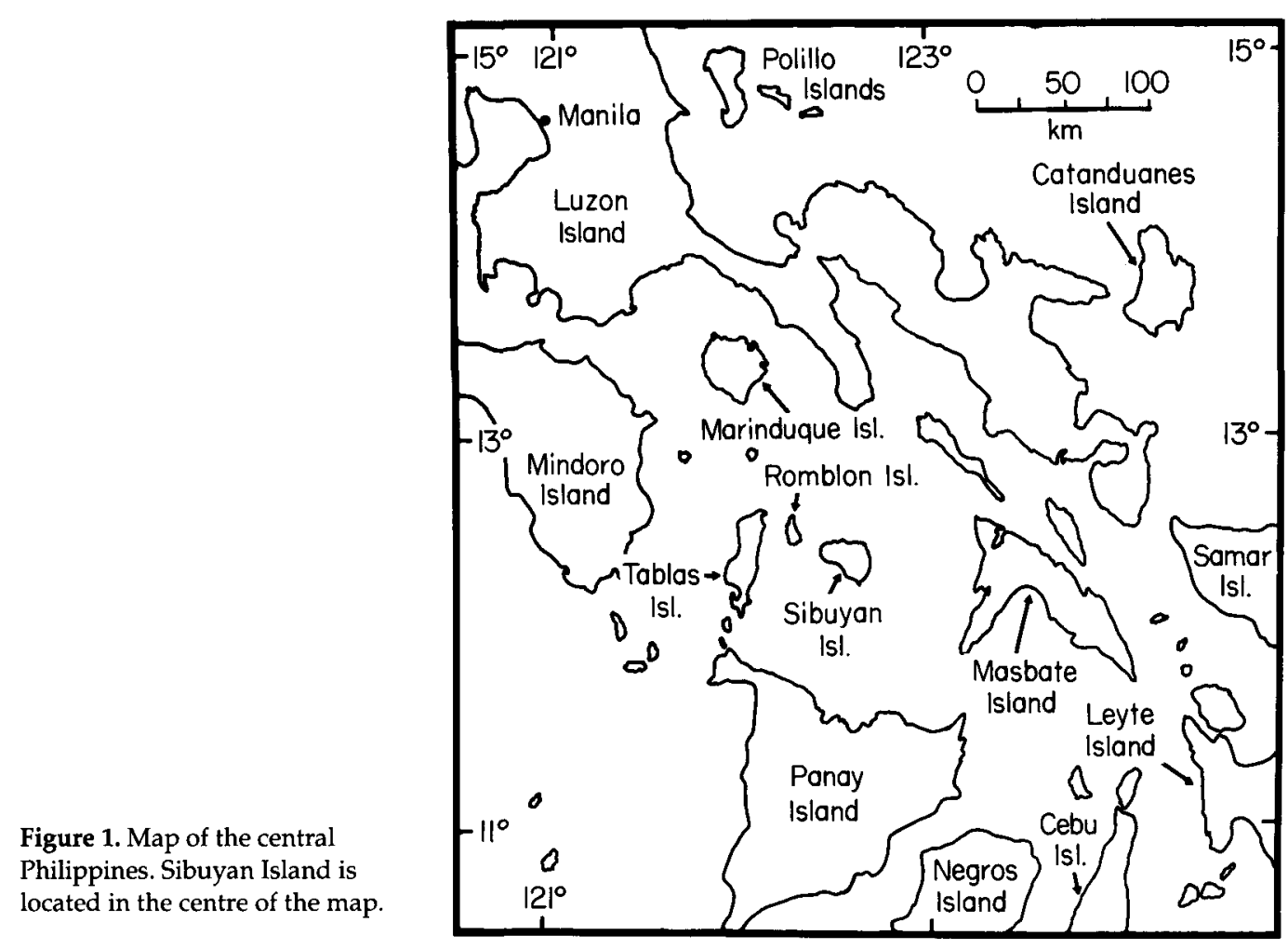

addressed on the dispersal patterns and origins of taxa colonizing across water rather than on Pleistocene land-bridge islands (e.g. Heaney et al., 1989).

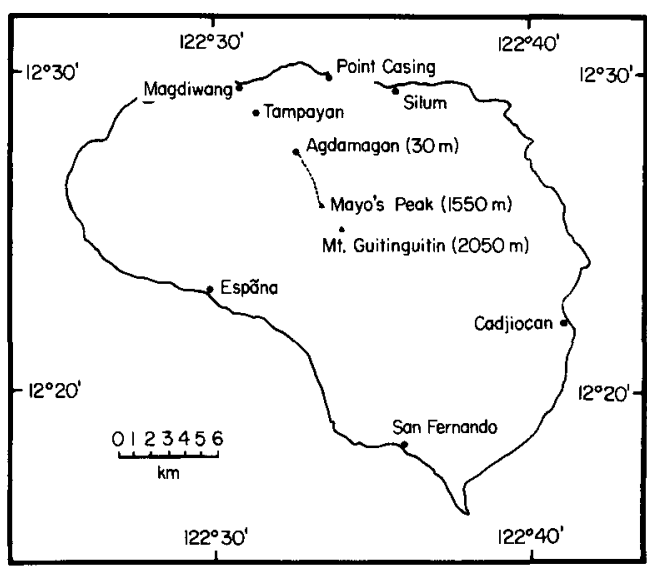

Figure 2. Map of Sibuyan Island. The dashed line represents the Agdamagan-Mayo's Peak trail. The Kuyasian Forest comes off the northern slopes of Mt Guitinguitin and the remaining low elevation portion is between Point Casing and Silum.
Sibuyan Island is an oceanic island surrounded by deep water, with a considerable amount of forest and substantial elevational relief (Figures 1 and 2). It is one of the few islands left in the Philippines with extensive areas of intact natural habitat, including lowland forest. Over one-half of the island, 100-150 sq $\mathrm{km}$, is forested (National Mapping and Resource Information Authority, 1987). In 1989 scientists from the Field Museum of Natural History and several Filippino institutions initiated collaborative inventories of the birds and mammals on Sibuyan Island, with particular reference to their altitudinal distribution. A detailed survey of the island's north side and an elevational transect were completed in the spring of 1992.

\section{Description of Sibuyan Island}

Sibuyan Island lies in the Sibuyan Sea and is surrounded by the larger islands of Luzon, Mindoro, Panay, and Masbate (Figure 1). The 
closest small islands, both to the west, are Romblon Island with the nearest shore-toshore distance of $12.5 \mathrm{~km}$, and Tablas Island with the nearest shore-to-shore distance of 34 $\mathrm{km}$; neither was connected to Sibuyan during the mid- to late Pleistocene. At its widest points, Sibuyan measures $24 \mathrm{~km}$ north to south and $28 \mathrm{~km}$ east to west, and has a total land area of $463 \mathrm{sq} \mathrm{km}$ (Anon., 1989). The major topographical feature is Mt Guitinguitin $(2050 \mathrm{~m})$ (Figure 2). Along the north-south axis of the island, the elevation rises from sealevel to over $2000 \mathrm{~m}$ in approximately $12 \mathrm{~km}$. The slopes of Mt Guitinguitin are generally steep and in some areas totally inaccessible to humans. The name of the mountain translates from the Ilonggo, the primary language spoken on the island, as 'saw-tooth', which refers to the series of precipitous jagged peaks that are conspicuous from the lowlands.

Five distinct natural habitats occur on Sibuyan Island: mangroves, lowland forest, montane forest, mossy forest and heathland (Brown, 1919; Whitmore, 1984). Mangrove swamps are found in numerous places along the sea coast. They are largely intact and human use is limited to some firewood cutting and exploitation of sea animals for food. However, in a few localities mangrove swamps have been converted into fish farms.

Across most of the island, lowland forest below $200 \mathrm{~m}$ has been cleared. The major exception is Kuyasian Forest on the north side, where continuous and relatively intact forest extends from the slopes of Mt Guitinguitin to sea-level, between Point Casing and the village of Silum (Figure 2). Along a trail leading from the village of Agdamagan to Mayo's Peak (Figure 2), the forest starts at $175 \mathrm{~m}$. The next $50 \mathrm{~m}$ of elevation is regenerating secondary forest. The lowest remaining large dipterocarp trees along this trail are at $225 \mathrm{~m}$ where there are clear signs of selective logging. Evidence of logging decreases at higher elevations, and disappears by about $625 \mathrm{~m}$. The zone between 650 and $700 \mathrm{~m}$ is transitional between lowland and montane forest, and between 725 and $1100 \mathrm{~m}$ the habitat is characteristically montane forest. From about 1150 to $1350 \mathrm{~m}$ the trail skirts narrow and ex- posed ridges, and the vegetation is dominated by thick climbing bamboo and, to a lesser extent, low-stature montane forest. At $1350 \mathrm{~m}$ the trail passes along a broader and less precipitous ridge, the bamboo ends abruptly and is replaced by mossy forest. This habitat continues up to Mayo's Peak (1550 m) except for exposed areas that have expanses of heathland. The ridge from Mayo's Peak to the summit of Mt Guitinguitin $(2050 \mathrm{~m})$ is mostly exposed rock with little vegetation.

\section{Biotic diversity of Sibuyan Island}

\section{Birds}

A total of 131 bird species have been recorded on Sibuyan Island, 24 of which are migrants and/or winter visitors. This is a relatively high number of species for an isolated oceanic island. When compared to the avifauna of $\mathrm{Mt}$ Isarog $(1966 \mathrm{~m})$, southern Luzon (the largest island in the Philippines), the numbers are remarkably similar - 135 species, of which 19 are migrants and/or winter visitors (Goodman and Gonzales, 1990). Along the elevational transect of Mt Guitinguitin, species number and density decrease with altitude. There is a small, but distinct, bird community restricted to the mossy forest zone, composed of Turdus poliocephalus and Zosterops montana. No endemic species of bird is known from the island.

\section{Mammals}

Fruit bats. Ten species of fruit bat (family Pteropodidae) have been recorded on Sibuyan Island, including an undescribed species of Haplonycteris (Goodman and Heaney, in prep.) and three species of flying foxes (Pteropus). Two individuals of the genus Nyctimene were netted in lowland forest at $40 \mathrm{~m}$ elevation. These specimens are currently under study, but preliminary findings indicate that they are similar to $N$. rabori, a species described in 1984, which is believed to be one of the rarest fruit bats in the Philippines and was previously known only from south-eastern 


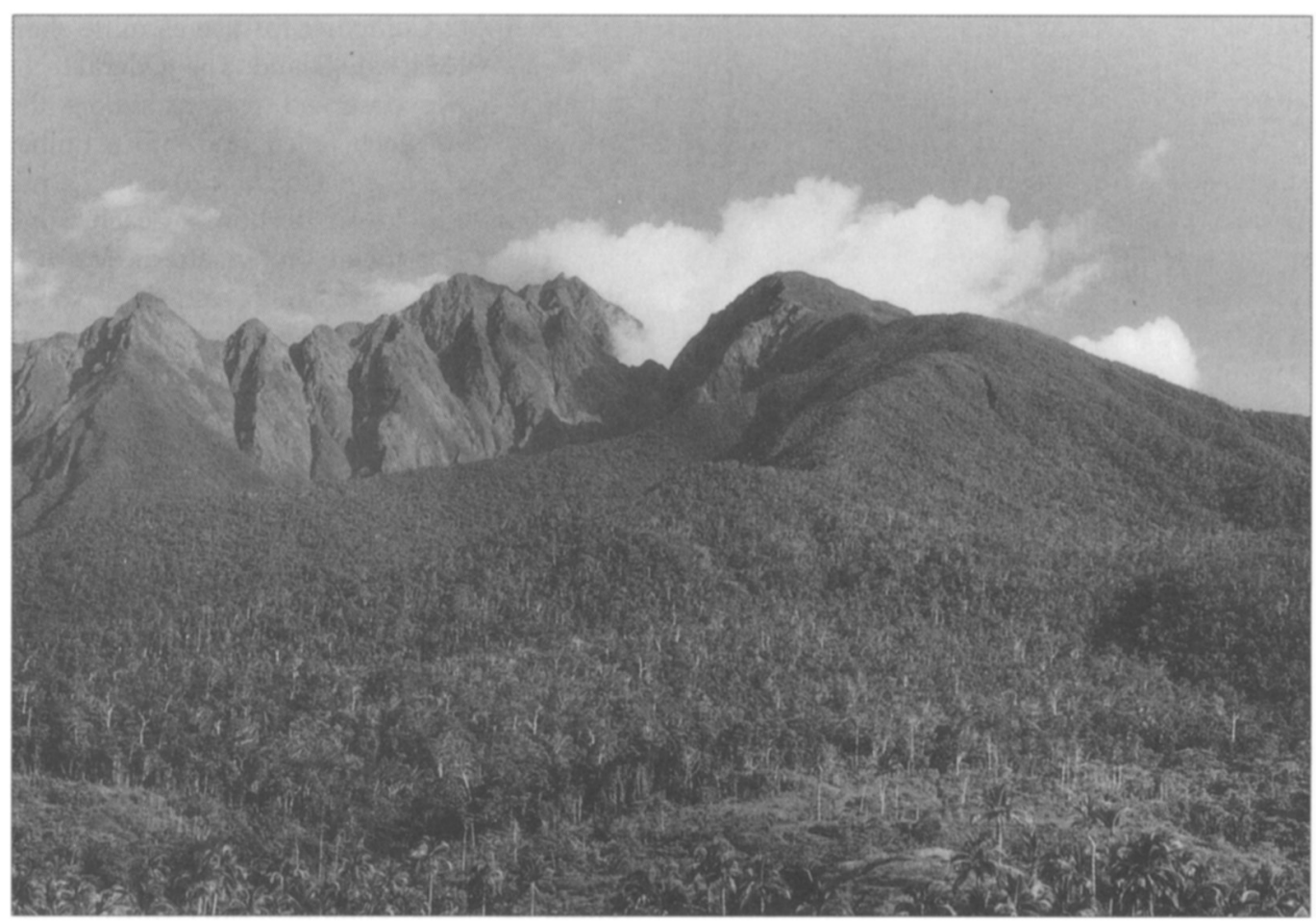

View of Mt Guitinguitin from the lowlands at Agdamagan. Note the jagged shape of the peaks. Guitinguitin means 'saw-tooth' in Ilonggo, the principal language of Sibuyan Island and nearby islands (S. M. Goodman).

Negros Island (Heaney and Peterson, 1984; Heaney and Heideman, 1987). When compared with other oceanic and land-bridge islands, or mountains of comparable size in the Philippines that have been well surveyed, the number of fruit bat species on Sibuyan Island falls well within the range for an island of its size (Heaney, 1991). However, Sibuyan is the smallest island in the Philippines that supports at least one species of endemic fruit bat. The other islands in the Philippines known to support island endemics, Palawan (11,785 sq $\mathrm{km})$, Negros $(13,670 \mathrm{sq} \mathrm{km})$ and Luzon $(108,171 \mathrm{sq} \mathrm{km})$, are larger than Sibuyan (463 $\mathrm{sq} \mathrm{km}$ ) by at least two orders of magnitude.

Rodénts. The known rodent fauna of Sibuyan Island shows a high level of endemism. The specimens gathered on the 1989 and 1992 trips are currently under study, but preliminary examination shows that there are several new to science: these may include two species of the genus Apomys, one species of Chrotomys, and one species related to Tarsomys (G. Musser, pers. comm.). Numerous rodent specimens from these collections have not yet been identified, and the known number of endemic species on the island might increase. There is an exceptionally high number of endemic rodents on this island, which further emphasizes its conservation importance.

Other mammals. One species of shrew (Crocidura) was found on the island. It has been provisionally assigned to $C$. mindorus pending further study (Heaney and Ruedi, in press). Macaques (Macaca fascicularis) are relatively common on Sibuyan from lowland forest adjacent to the sea up to montane forest.

\section{Habitat degradation of Sibuyan Island: the need for protection}

Sibuyan Island is one of the few remaining places in the Philippines with relatively intact 


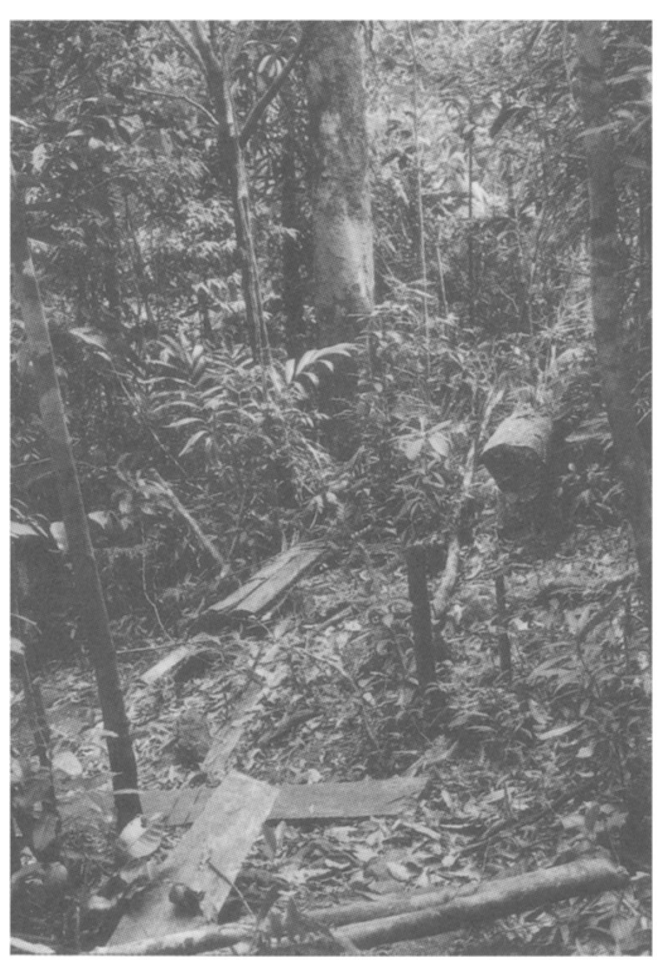

Cut tree in the Kuyasian Forest. The mid-section of the tree has been cut, squared, and removed (N.R. Ingle).

and extensive lowland forest. On most islands, the lowland forest has been totally cleared up to $500 \mathrm{~m}$ or higher. Sibuyan is highly unusual among the thousands of islands in the country in that enough natural habitat remains to conduct surveys along an elevational transect starting from near sea-level, and passing through continuous lowland, montane and mossy forest.

The Kuyasian Forest, the only remaining coastal lowland forest on Sibuyan Island, is being logged rapidly. During our stay there, between 11 and 20 March 1992, each day from dawn to dusk we could hear chainsaws in the nearby hills. Although there was no legal logging concession on Sibuyan Island during this period, these activities were common knowledge and condoned by government and village officials. In at least two cases, the chainsaw operators were relatives of local officials.

Most, if not all, of the timber resulting from this logging activity was commissioned by the
Atlas Mining Company for use as mine shaft supports on Masbate Island. The general technique that we observed was to square the mid-section of each felled tree into a timber measuring $6^{\prime \prime} \times 8^{\prime \prime} \times 8^{\prime}(15 \mathrm{~cm} \times 20 \mathrm{~cm} \times 2.4 \mathrm{~m})$. The upper and lower portions of each trunk were not utilized. Late on two afternoons during our stay in Kuyasian Forest, there was a burst of activity on the adjacent slopes as groups of people carried, dragged and tumbled the logs down from the hills, and stacked them along a nearby road. After dusk, the squared timbers were loaded on to trucks and driven to Silum where a boat was waiting to transport them to Masbate Island.

We observed at least two separate shipments of logs being removed from the immediate area; the first, on the night of 15 March, consisted of 180-200 timbers and the second, on 23 and 24 March, of at least 100 timbers. On 25 March 1992, after we had left the area, another shipment was being prepared and consisted of at least 40 timbers ( $R$. Timmins, pers. comm.). Thus, during the course of 10 days in mid- to late March, a minimum of $3206^{\prime \prime} \times 8^{\prime \prime} \times 8^{\prime}$ timbers left the slopes of the Kuyasian Forest adjacent to our camp. About 20 years ago the Atlas Mining Company had a logging concession in the hills just above Silum; most of this area, up to about $100 \mathrm{~m}$, is now non-native grassland or heavily disturbed secondary forest. On 11 March 1992, we saw at least five people hauling logs down from the hills above Silum, that were cut and squared to similar specifications as those being removed from other areas of the Kuyasian Forest. It appears that the continued local exploitation of timbers for the Atlas Mining Company is widespread throughout the forest, and not limited to the slopes near our camp.

We were told that in early March 1992 the Atlas Mining Company placed an order for an equivalent of 80,000 board feet of these timbers to be delivered to their Masbate Island mining project by the end of the month. It is unknown what proportion of these timbers were being extracted from the Kuyasian Forest or from Sibuyan Island in general. However, given that each single $6^{\prime \prime} \times 8^{\prime \prime} \times 8^{\prime}$ 
Cut and squared timbers ready for shipment to Atlas Mining Company, Masbate Island. Each timber measures $6^{\prime \prime} \times 8^{\prime \prime} \times 8^{\prime}(15$ $\mathrm{cm} \times 20 \mathrm{~cm} \times 2.4 \mathrm{~m})($ N. R. Ingle $)$.

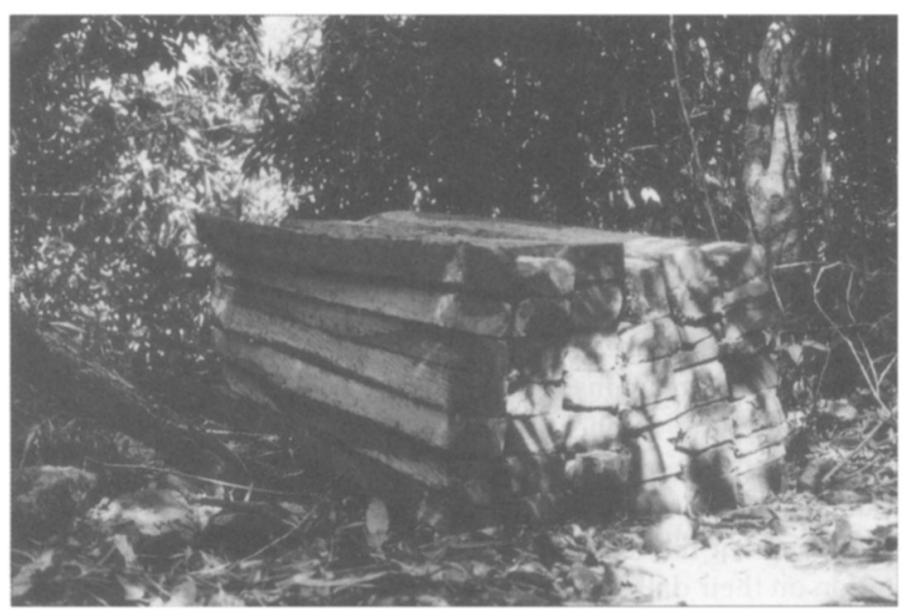

timber is approximately 32 board feet (Forbes, 1956), and represents a single tree, more than 2500 trees were required to fill this order.

Other forest areas are being illegally exploited for timber, particularly accessible lowland forest on the north side of $\mathrm{Mt}$ Guitinguitin (up to $600 \mathrm{~m}$ ). At the lower elevations, caraboa are used to remove the logs; on higher ground, labourers drag and carry them out. In areas that are being selectively logged, there is a clear reduction in the diameter at breast height of standing trees and, thus, a reduction in the stature of the forest.

\section{Recommendations and conclusion}

At the current rate of timber extraction, the remaining lowland forests on Sibuyan Island below $200 \mathrm{~m}$ will be gone within a few years. Once widespread throughout the Philippines, this habitat now exists only at a few isolated places in the archipelago, and any remaining lowland forest needs immediate attention. The extensive areas of other forest types, the remarkable terrestrial vertebrate fauna, and the unusual geological history warrant immediate conservation efforts on Sibuyan.

The illegal lumber operations on Sibuyan Island are relatively small and controlled by local officials and businessmen. Presumably due to the island's size, remoteness, and steep slopes, major logging operations, controlled by powerful companies, have not been estab- lished. The current activities are relatively small-scale, generally employing one chainsaw operator and a few assistants, and timber exportation is organized by a local middleman. Thus, some problems regarding forest protection encountered elsewhere in the Philippines, such as threat or bodily harm to individuals or agencies intervening and attempting to stop logging activities, are not apparent on Sibuyan Island. Except for logging operations for the export of timbers to Masbate Island, the level of forest exploitation by people living on the island is generally low. Thus, in our opinion the illegal logging on Sibuyan Island is extensive enough to be a serious threat to the remaining lowland forest, but the nature of these operations is simple enough that the enforcement of laws that regulate logging in the Philippines should be sufficient to curb these activities.

The regional office of the Department of Environment and Natural Resources (DENR) has eight forest guards whose task it is to patrol the remaining forested areas of Romblon Province; basically the islands of Romblon, Tablas and Sibuyan. On the basis of analyses of satellite images (National Mapping and Resource Information Authority, 1987), Romblon is completely deforested, Tablas has two remaining forest parcels that together cover less than 500 ha, and Sibuyan has $10,000-15,000$ ha of forest (approximately onehalf of the total island surface area).

Currently, the remaining forests of Sibuyan 
Island have no special status or legal protection. We recommend that immediate action be taken to place them within the protected areas system of the DENR. The provincial forest guards should focus their activities on Sibuyan, and if financially possible more guards need to be employed. Strict enforcement of regulations is critical, and when logging operations are discovered, legal action should be taken against the exporters, middlemen, and the higher organization levels. Further, educational programmes need to be established at grass-roots level, to inform people about the long-term effects of deforestation on their daily lives.

\section{Acknowledgments}

We are grateful to several Filippino government agencies and institutions for facilitating our work, particularly Samuel Peñafiel, Carlo Custudio and Marlynn Mendoza of Protected Areas and Wildlife Bureau, Department of the Environment and Natural Resources; Pedro C. Gonzales, National Museum of the Philippines; and Arthur R. Tansiongco, Municipal Mayor, Magdiwang. Other participants in the Sibuyan surveys included Danilo Balete and Lawrence Heaney in 1989 and Thomas Gnoske and David Willard in 1992. On Sibuyan Island, we warmly acknowledge the gracious hospitality of the J. Lee Tansiongco family and numerous other people in Tampayan, and the companionship of Wilson Villaneuva and Bermar Tansiongco. Our research was financially supported by the Field Museum of Natural History. For comments on an earlier version of this paper we are grateful to Lawrence R. Heaney, Paul D. Heideman, Eric A. Rickart, and William T. Stanley.

\section{References}

Anonymous. 1989. Municipal Profile, Politico-socioeconomic and Comprehensive Development Plan. Municipality of Magdiwang, Magdiwang, Province of Romblon.

Brown, W.C. and Alcala, A.C. 1970. The zoogeography of the herpetofauna of the Philippine Islands, a fringing archipelago. Proc. Calif. Acad. Sci. 38, 105-130.
Brown, W.H. 1919. Vegetation of Philippine Mountains. Bureau of Printing, Manila.

Dickinson, E.C., Kennedy, R.S. and Parkes, K.C. 1991. The Birds of the Philippines. British Ornithologists' Union Checklist No. 12.

Forbes, R.D. 1956. Forestry Handbook. The Ronald Press Company, New York.

Goodman, S.M. and Gonzales, P.C. 1990. The birds of Mt Isarog National Park, southern Luzon, Philippines, with particular reference to altitudinal distribution. Fieldiana: Zoology, new series, No. 60 .

Heaney, L.R. 1984. Mammals from Camiguin Island, Philippines. Proc. biol. Soc. Wash. 97, 119-125.

Heaney, L.R. 1986. Biogeography of mammals in SE Asia: estimates of rates of colonization, extinction and speciation. Biol. J. Linnean Soc. 28, 127-165.

Heaney, L.R. 1991. An analysis of patterns of distribution and species richness among Philippine fruit bats (Pteropodidae). Bull. Am. Mus. nat. Hist. 206, 145-167.

Heaney, L.R., Gonzales, P.C. and Alcala, A.C. 1987. An annotated checklist of the taxonomic and conservation status of land mammals in the Philippines. Silliman J. 34, 32-66.

Heaney, L.R. and Heideman, P.D. 1987. Philippine Fruit Bats: endangered and extinct. Bats, 5, 3-5.

Heaney, L.R., Heideman, P.D., Rickart, E.A., Utzurrum, R.B. and Klompen, J.S.H. 1989. Elevational zonation of mammals in the central Philippines. J. Trop. Ecol. 5, 259-280.

Heaney, L.R. and Peterson, R.L. 1984. A new species of tube-nosed fruit bat (Nyctimene) from Negros Island, Philippines (Mammalia: Pteropodidae). Occasional Papers, University of Michigan Museum of Zoology, No. 708 .

Heaney, L.R. and Ruedi, M. In press. A preliminary analysis of biogeography and phylogeny of Crocidura from the Philippines. Carnegie Museum of Natural History, Special Publication.

National Mapping and Resource Information Authority. 1987. Romblon, sheet 2518, 1:250,000 series. Fort Bonifacio, Manila.

Whitmore, T.C. 1984. Tropical Rain Forests of the Far East, 2nd edn. Clarendon Press, Oxford.

Steven M. Goodman, Field Museum of Natural History, Roosevelt Road at Lake Shore Drive, Chicago, Illinois 60605, USA.

Nina R. Ingle, Environmental Research Division, PO Box 2232, 1062 Manila, Philippines. 